\title{
Narrar para saber quiénes somos. Grafiticiudad y visión en trávelin: el contexto de la imagen, la ciudad y la palabra
}

\author{
Carlos Roberto da Costa \\ Faculdade Cásper Líbero, Brasil \\ ccosta@casperlibero.edu.br
}

José Geraldo de Oliveira

Universitat Autònoma de Barcelona, España

zegera@hotmail.com

Recibido: 18/7/2018 / Aceptado: 28/9/2018

doi: 10.26439/contratexto2018.n030.3158

\begin{abstract}
Resumen. Grafiticiudad es un espacio de acción en el que agentes se apropian estéticamente de la ciudad y la transforman en una plataforma productora de imágenes. La propuesta de este ensayo es una reflexión acerca del paisaje urbano como una narrativa a través de la acción de los grafiteros, agentes contemporáneos de comunicación y de apropiación del espacio urbano. Un territorio de metáforas en movilidad que en su carácter efímero reúne puntos de tensiones dialécticas. Un paisaje ritmado por la interacción del observador en movimiento que produce miradas en los intersticios urbanos, ya que el cuerpo del observador también está allí y desea interactuar. El transeúnte puede percibir fragmentos de las varias ciudades contenidas en la urbe, en que los grafiteros imponen una comunicación que transita entre la agresividad y la pasividad del observador, al mismo tiempo en que buscan crear un territorio de diálogos híbrido donde confluyen las tensiones, la pertenencia, la identidad. Así el grafiti adquiere una base político-social, provocando el debate entre lo que es público y privado y cuestionando el mismo concepto de arte. Esa base es compuesta por líneas o rizomas, sin centro, donde la necesidad de identidad y pertenencia aflora.
\end{abstract}

Palabras clave: grafiticiudad / visión en trávelin / ciudad / espacio urbano / grafiti 


\title{
Narrating to know who we are. Graffiticity and travelling vision: the context of words, images and the city
}

\begin{abstract}
АвsтrAct. Graffiticity is a space of action in which graffiti artists esthetically take the city and transform it into an image-producing platform. The proposal of this essay is a reflection on the urban landscape as a narrative through the action of graffiti artists, contemporary agents of communication and appropriation of urban space. Said space is a territory of moving metaphors that, in its ephemeral nature, gathers points of dialectical tensions; a landscape rhymed by the interaction of the moving observer that produces glances in the urban interstices, since the observer's body is also there wanting to interact. The bystander can perceive fragments of various cities contained in the city, where graffiti artists impose a communication that goes from the aggressiveness to the passivity of the observer and seek to create a territory of hybrid dialogues where tensions, belonging and identity converge. Thus, graffiti acquires a political-social base, generating debate between what is public and private, and questioning the proper concept of art. That foundation is composed of lines or rhizomes, without a center, where the need for identity and belonging emerges.
\end{abstract}

Keywords: graffiticity / travelling vision / city / urban space / graffiti 


\section{Grafiticiudad como plataforma productora de imágenes}

$\mathrm{E}$ 1 objetivo de este ensayo es una reflexión acerca del paisaje urbano como narrativa, específicamente a partir de la acción de los hacedores de grafiti y de este como dispositivo comunicativo urbano; o sea, es una reflexión acerca de la apropiación del espacio urbano que se manifiesta en una acción de comunicación en cuyos intersticios acontecen narrativas visuales en busca de identidad y pertenencia de sus imágenes. ¿Cómo ocurre, entonces, la visión y la percepción en la urbe y cómo nuestra conducta se comporta en ese contexto?

El término grafiticiudad, unión de las palabras grafiti y ciudad, pasa a indicar un espacio de acción, colectiva o no, que se apropia estéticamente de los no-lugares (Foucault, 2010) para explorarlos y transformarlos en una plataforma productora de imágenes. Estas producen experiencias sensoriales, sea para cuestionar la realidad social o para interferir estéticamente, transformando zonas de tránsito en espacios "vividos", "concebidos" y "percibidos", utilizando la nomenclatura de Henri Lefebvre (2013). En la grafiticiudad, el campo visual se convierte en una superficie de inscripciones y un espacio de aglutinación de perspectivas y lenguajes. Pensar en la grafiticiudad es, por tanto, proponer una nueva forma de visualidad en la que nuestra mirada cambia y multiplica los puntos de vista.

La imagen se convierte en el núcleo de la metrópoli y el retrato de sus múltiples identidades: un territorio de metáforas que en su movilidad y en su condición efímera reúne puntos de tensiones dialécticas; un paisaje con ritmo, enunciaciones surgidas en la interacción del observador en movimiento (de ahí la expresión visión en estado de trávelin) ${ }^{1}$, que produce una conjunción de miradas en los intersticios urbanos ya que el cuerpo del observador también se hace presente y el observador no es un mero receptor pasivo, él codifica y decodifica, devolviendo su (re)significación a esa cacofonía de elementos.

Las representaciones visuales en esta plataforma, a la que el caminante trasforma en otra cosa a cada significación espacial, deben ser tratadas bajo el criterio de la complejidad. Cuando hablamos de complejidad y ciudad estamos haciendo referencia a lo que está tejido en conjunto. Es decir, a lo que está interrelacionado, entrelazado. Las ciudades no están constituidas como una unidad sustancial, sino que se construyen como una unidad relacional regida, ordenada, sustentada y articulada por relaciones de y entre las distintas dimensiones, partes o subsistemas que

1 Una referencia a trávelin (del inglés travelling). Técnica cinematográfica que consiste en desplazar una cámara montada sobre unas ruedas para acercarla o alejarla al sujeto u objeto que se desea filmar. 
la configuran. En otras palabras, la ciudad no es solo la construcción física, sino una red de relaciones en las que el discurso visual es expansivo y está enfocado en una constelación de significados que contiene distintas gramáticas visuales fabricadas colectivamente.

De esta forma, la grafiticiudad pasa a ser aprehendida por el observador como una forma de montaje cinematográfico, un modo de montaje subjetivo, una relación que mantiene con los tramos recorridos, asignada a partir de la unión de varios signos y símbolos que remiten a la percepción de un análisis también fragmentado; o sea, un montaje como fragmentación y reunión de bloques de un material visual que modifica su estructura y configura la percepción del caminante (Bolle, 1996).

Este fenómeno es impuesto en las metrópolis a través de inscripciones urbanas que pasan a constituir un "sistema ecológico de comunicación" y crear un nuevo espacio al que se puede llamar espacio hipnótico. En él, los elementos de comunicación se entrelazan $y$ se convierten en un elemento estético-sensorial que emerge de la transitoriedad y de la condición de efímero.

Según Joan Costa (2011), la ecología de la comunicación es una ciencia de las relaciones e interacciones que existen entre las diferentes especies de actividades de comunicación dentro de un sistema social disperso en un territorio. Así, es posible pensar los fenómenos comunicativos más allá de la comprensión meramente instrumentalista y asumirla como un ecosistema. Es decir, cuando planteamos la idea de un "sistema ecológico de comunicación" en el contexto de la grafiticiudad, nos referimos a un enfoque que integra, bajo la metáfora del ecosistema, los procesos comunicativos, así como la interrelación entre ellos. También se considera el modo en que se construye, a partir de todo ese conjunto de interacciones, el vínculo entre los humanos que se comunican, incluso considerando al grafiti entre los dispositivos por medio de los cuales se comunican.

Es posible pensar este espacio, a partir de Gilles Deleuze y Félix Guattari (2004), como una plataforma que territorializa y desterritorializa como procesos concomitantes, fundamentales para comprender las prácticas humanas en un espacio urbano en el que se mezclan los ritmos, la inestabilidad, el movimiento y la duración. De la misma forma, ese espacio tiene funcionalidad propia: la naturaleza informacional con que la comunicación gana contornos propios, ya que la explosión de signos agota y lleva a la destrucción de sentidos. "El visual no es solo la imagen, sino un fenómeno complejo que circula en diferentes plataformas y niveles de significado, todos inscritos en la visualidad" (Català, 2011, p. 19).

\section{Las visiones de la ciudad}

La ciudad es un tema recurrente en la obra de Walter Benjamin. En 1923 él tradujo al alemán Tableaux parisiens (Cuadros parisinos) de Charles Baudelaire. Posteriormente, llevó a cabo sus trabajos 
Calle de sentido único, Diario de Moscú, Crónica de Berlín, la serie radiofónica sobre Berlín, e Infancia en Berlín hacia mil novecientos, hasta dedicarse, entre los años 1927 y 1940, a su proyecto inacabado El libro de los pasajes.

La metrópoli es presentada por el pensador alemán como morada e imagen mental del colectivo: territorios múltiples de conflicto social y de transformación urbanística. Situada en una época de grandes cambios (el periodo entre guerras y las reformas urbanísticas promovidas por el barón Haussmann), París se convierte en una ciudad habitada por hombres que se pierden en laberintos y espacios sensoriales, multitud de imágenes donde, para Benjamin, "nadie es para el otro ni totalmente nítido ni totalmente opaco" (Benjamin, 1989, p. 46).

Las nuevas técnicas de reproducción, entre ellas el cine, surgieron a partir de la segunda mitad del siglo xix. En esa perspectiva, él se propone pensar los cambios que configuran la modernidad a partir de las transformaciones de los modos de percepción y recepción de la experiencia social de las colectividades humanas en los centros urbanos.

Para Benjamin, las obras, incluso las urbanísticas y arquitectónicas, poseen enigmas y dejan mensajes para el futuro. "Son los residuos de un mundo soñado" (Benjamin, 2012, p. 63), y es en ese contexto que ellas pueden ser comprendidas integralmente. "La construcción de la mirada sobre la ciudad se da a través de imágenes dialécticas, fragmentos [...] y técnicas de montaje, configurando un ensayo 'cinematográfico', una 'radiografía' de la metrópoli" (Bolle, 2000, p. 19).

Ante ese caleidoscopio, se impone al observador una acción que desplaza nuevas "constelaciones" de formas, y la percepción implica interpretar no solo los signos explícitos, sino, según Benjamin, "atenerse a los desechos, al efímero, al despreciado" (2009, p. 502) por medio del montaje. Esta fue una práctica apropiada por los surrealistas, cuyos montajes consistían en reunir imágenes de manera inaudita con el propósito de "desconcertar el mundo exterior y desalojar las imágenes del mundo exterior del lugar que ellas habían tomado el hábito de ocupar y recolocar las imágenes en el pensamiento" (Cassou, 1962, p. 423).

El flâneur, en la literatura de Charles Baudelaire, está íntimamente vinculado a la construcción de lo moderno. Como una entidad que camina por la ciudad, el flâneur elige un punto de vista con el fin de aprehenderla. Es tomado por ella, pero se mantiene alejado al salir. Una posición de "viajero del imaginario" que se vuelve cercano y lejano, y por eso tiene la capacidad de percibir su fugacidad -lo que Benjamin (2009, p. 465) definió como "dialéctica de la flânerie"-, penetrar en la multitud con el objetivo de estar en el otro y percibir la realidad, abandonando la idea del pathos de la distancia y el modelo perspectivo renacentista.

Baudelaire describe la metrópoli metafóricamente como la experiencia embriagadora de tomar un "baño de 
multitud", lo que añade Benjamin en El libro de los pasajes (2009), un observador con la pasión y la profesión de "desposar a la multitud", un caminante del "gran desierto de hombres". Se instaura, así, un culto al frenesí urbano, una apología a la multitud y a la "embriaguez religiosa de las grandes ciudades" (Benjamin, 2009, p. 335).

Benjamin crea una representación de la vida tumultuosa considerando dos conceptos vigorosos de su época: centro y periferia, algo que, como veremos, la grafiticiudad diluye, pues las fronteras se rompen en la existencia de varios centros $\mathrm{y}$, consecuentemente, distintas periferias que se renuevan cotidianamente y modifican la forma de circulación.

¿Cómo pensar esa experiencia de la modernidad en el diseño comunicativo de la grafiticiudad? En ese espacio, ¿cómo identificar elementos comunicativos, puesto que todo puede ser información y no todo puede comunicarse? En el universo de la grafiticiudad, y apropiándose del "rizoma urbano", el creador de grafitis es la actualización de la figura del flâneur, actuando en el espacio/tiempo, desplazándose en el intento de hacer efectiva la pertenencia a una calidad nueva: información y comunicación. Esto sucede porque el lugar es siempre mutable y es, a la vez, el mismo lugar en la memoria, el mismo de siempre $y$, al mismo tiempo, otro. Además, su fuerza de intervención, "la memoria la debe a su misma capacidad de poder alterarse: pude desplazarse, es móvil y no tiene lugar fijo" (De Certeau, 2000, p. 96).

Las nuevas formas comunicativas se reconfiguran en el espacio de la vivencia de lo efímero y lo transitorio. Joan Fontcuberta (2010) señala que estamos viviendo en un mundo de imágenes y que no buscamos "la visión, sino el déjà-vu". De la misma forma Josep M. Català (2011) afirma que el fragmento es una característica de la estética fluida de la modernidad. En ese marco, el observador, que absorbe una información fragmentada, se abre al pensamiento de una "arquitectura del imaginario" como puerta o ventana para una visión calcada en hipertextos ${ }^{3}$.

2 Es una aproximación a la exposición y aplicación de los principios elaborados por Deleuze y Guattari (2004): los seis principios de la teoría del rizoma fueron los de conexión, heterogeneidad, multiplicidad, ruptura asignificante, cartografía y cacofonía. A partir de esta formulación es posible entender, entre muchos significados e interpretaciones posibles, que en un sistema rizomático todos los puntos pueden ser conectados a otros, independientemente de su naturaleza, y ese sistema puede ser roto en cualquier parte, y sufrir construcciones y mutaciones constantemente, ilustrando procesos de territorialización, desterritorialización y reterritorialización.

3 A pesar de no ser el foco de este ensayo, en este acto comunicativo es importante el sujeto interpelado, aquel que ante la circunstancia se revela con voluntad de mirar y observar. Sin embargo, ¿qué pasa con aquel que ve, pero obvia y continúa con su desplazamiento? La experiencia racional de observar conduce a procesos cognitivos diferenciados de aquel que solo ve y transita. ¿Cuál puede ser su papel en un proceso de comunicación donde el mensaje no cumple su cometido? Son necesarias futuras investigaciones. 
En el caminar y en la percepción de lo minúsculo en la contingencia de la multitud, la "visión de la ciudad" o "formas de miradas producidas por la ciudad" son generadas vía hipertextos. Según Català, el término hipertexto, asociado ahora también al universo de la computación, antes era usado primordialmente sobre estructuras literarias clásicas, y es una instancia importante de la tendencia a la visualización de la cultura contemporánea, pues la "ruptura del texto lineal que comporta constituye una manera de transformarlo en imagen" (Català, 2011, p. 100).

\section{La ciudad como palimpsesto: imagen arquetípica para la lectura del mundo}

La palabra palimpsesto, de origen griego, significa 'grabado nuevamente', y fue usada para denominar un pergamino que, hecho de material costoso (como piel de animales), tuvo su texto raspado para recibir nueva inscripción por economía de material. Lo que importa aquí es el concepto de 'revelar lo que está abajo' en la superposición de mensajes. De esta manera, podemos relacionar la ciudad con un palimpsesto y el grafiti con la escritura, que no siempre cubre lo anteriormente escrito en el soporte arquitectónico en que está insertado.

Según Sandra J. Pesavento (2004), Gérard Genette utiliza la figura del palimpsesto para elaborar una teoría para los análisis del texto literario como portador de otros textos en él escondidos. Este procedimiento que Genette establece para el mundo del texto y de la lectura puede ser trasladado a otras instancias, como, por ejemplo, aquella que lidia con la historia, la memoria, la ciudad, añade Pesavento. Y, en cuanto a la ciudad, empezamos por la materialidad, este espacio construido que se expone de forma arquitectónica y en el trazado urbano, perceptibles al mirar. Como dice el teórico francés, citando al escritor Thomas de Quincey: "el palimpsesto de la memoria es indestructible, es siempre posible rescatar, por la evocación, experiencias y sensaciones dormidas" (Genette, 1989, p. 7).

La ciudad contemporánea tiene por lo menos tres rasgos comunes: identificatoria (pertenencia e identidad), relacional e histórica (memoria); en ella es posible encontrar palimpsestos de imágenes que se ofrecen como verdaderos enigmas por ser descifrados, pues sus estratos funcionan como la acumulación de marcas de historicidad imagética superpuestas en el tiempo y que se amplían más allá de los trazos materiales o de escrita. La memoria penetra entre esas "imágenes" (figura 1). Esas marcas se pueden recuperar como metáfora para abordar el pasado de una ciudad. O en las palabras de Pesavento:

Hay un tiempo que se ha derramado, pero que ha dejado huellas que pueden ser recuperadas. Hay una superposición de capas de experiencia de vida que incitan al trabajo de una defoliación, de una especie de arqueología de la mirada, para la obtención de aquello que se encuentra oculto, pero que ha dejado huellas, tal vez imperceptibles, que hay que descubrir (Pesavento, 2004, p. 26). 
Figura 1. El grafiti como palimpsesto de la memoria de la ciudad

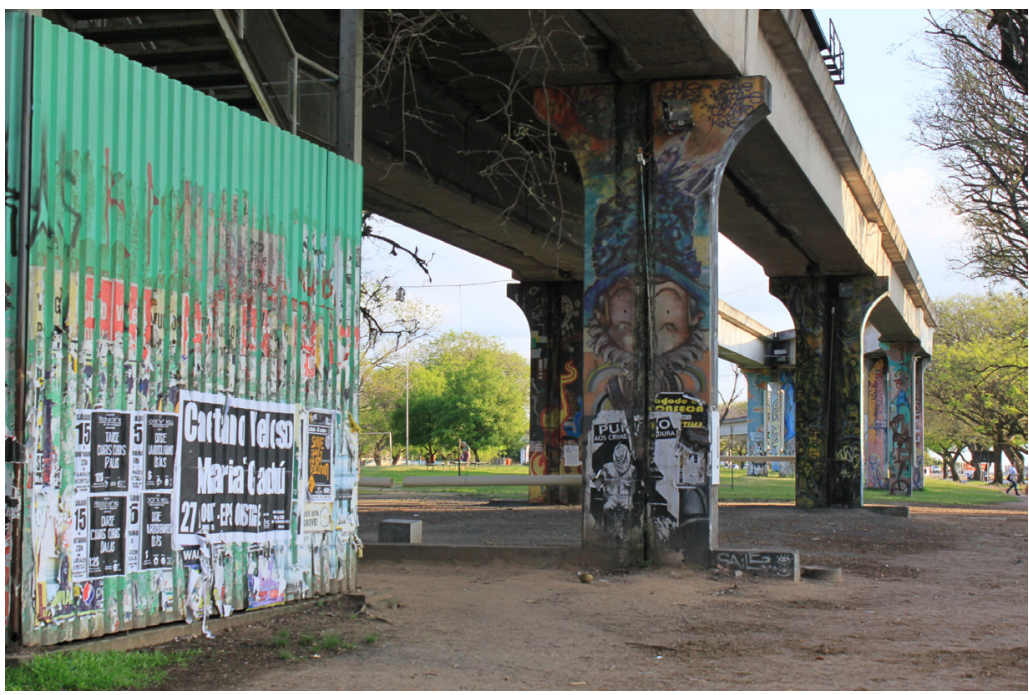

Gasômetro, Porto Alegre, Brasil

Fuente: archivo personal de los autores

Estos acumulativos urbanos (visuales) se sitúan más allá de las marcas de la historicidad temporal y resuenan pasando los rasgos materiales y alcanzando el plano cultural. En el contexto de la semiosfera ${ }^{4}$, el texto es un mecanismo funcional que constantemente se recrea, generando nueva información, así como lo indica Yuri M. Lotman: "el texto sacado del contexto es una pieza de museo: un depósito de una información constante" (Lotman, 2000, p. 103). Esto hace que pierda su función primaria de generar conocimiento. Sin embargo, de forma especulativa, es posible realizar esa separación (del texto y su contexto),

porque todo texto (texto de cultura) en alguna medida complejo tiene la capacidad de recrear a su alrededor un aura contextual y, al mismo tiempo, de entrar en relaciones con el contexto cultural del auditorio. En segundo lugar, porque

4 Según Lotman, la semiosfera funciona como un espacio de contención ante la violencia del mundo, el cual es formado por códigos. Es el mundo de los signos en el que todos los humanos viven e interactúan. Los signos son representaciones que conforman un espacio delimitado respecto del espacio que lo rodea, que sería el espacio extrasemiótico. Estos ámbitos se encuentran divididos por una frontera de puntos que pertenecen a ambos espacios, ella actúa como filtro y como traductor. 
todo texto complejo puede ser considerado como un sistema de subtextos para los que él actúa como contexto, cierto espacio dentro del cual tiene lugar el proceso de la formación semiótica del sentido. (Lotman, 2000, p. 103)

Cuando consideramos la ciudad como un sistema comunicativo abierto, por donde circulan cuerpos, ese espacio crea pasajes que posibilitan visualizar lo que puede existir en bajo, entre y sobre las capas de los palimpsestos espacial y temporal. La producción imagética en la grafiticiudad se configura como una imagen compleja en que ocurre tensión y es en ese umbral que se efectúa la comunicación y la generación de sentidos. Esos códigos tramados bajo, entre y sobre las capas crean pasajes para nichos imagéticos que remiten a conexiones para decodificar la metrópoli. Las imágenes urbanas, incluso raspadas y rediseñadas, guardan la posibilidad de nuevas lecturas para comprender las culturas y sus signos.

En cuanto a la ciudad, es posible percibir que la mirada se prende en detalles de construcciones arquitectónicas, ora ordenadas, ora desordenadas. Podemos pensar que cualquier imagen en ese espacio es solo un punto del pasado, una imagen en un cementerio de palimpsestos. No hay "presente" en la imagen de la ciudad. Y así como el pensamiento, nuevas cartografías subjetivas son trazadas en todo instante. $\mathrm{La}$ imagen de la ciudad solo puede ser (re) construida por el efecto de la memoria, que no sigue un orden lineal de agrupamiento de esos recuerdos. Las imágenes se montan y se fragmentan, y reorganizadas se vuelven palimpsestos, metáforas de conexiones de imágenes. Si pensamos en la formación de un pensamiento visual, al caminante en la ciudad se impone la fragmentación del paisaje.

El investigador Willi Bolle, en "As siglas em cores no Trabalho das Passagens, de W. Benjamin" (1996), afirma que

[las existencias de] afinidades entre la topografía de la gran ciudad y las estructuras mentales de sus habitantes era una concepción cara para Benjamín: “Desde hace muchos años estoy jugando con la idea de organizar el espacio de la vida (bios) gráficamente, en la forma de un mapa". (Bolle, 1996, p. 55)

Para Bolle, el pensador alemán imaginó un mapa de una ciudad que se "equivale a la cartografía de su vida afectiva", o un "mapa mnemónico de Berlín estrictamente personal" (Bolle, 1996, p. 55) ${ }^{5}$.

5 El arquitecto italiano Francesco Careri, en Walkscapes, el andar como práctica estética (2014), nos guía por diferentes episodios históricos tomando como eje el tema del andar como un acto cognitivo capaz de transformar el espacio y su significativo. También Kevin Lynch en La imagen de la ciudad (1998) sienta una referencia fundamental para entender cómo se conforma la imagen de la ciudad y de qué instrumentos disponemos a la hora de intervenir en ella. A través de la investigación de tres ciudades (Boston, Jersey City y Los Ángeles), Lynch establece los cinco elementos clave de interacción visual con la ciudad (vías, bordes, barrios, nodos e hitos) y proporciona un análisis que explora la percepción y la interacción de las personas con la forma y el entorno urbanos. 
Cuando esté viejo, me gustaría tener en el pasillo de mi casa / Un mapa Pharus de Berlín / Con una etiqueta / Puntos azules designarían las calles donde viví / Puntos amarillos, los lugares donde vivían mis novias / Triángulos marrones, las tumbas / En los cementerios de Berlín donde yacen los que estuvieron cerca de mí / Y líneas negras rediseñan los caminos / En el Zoológico o en el Tiergarten / Que recorrí conversando con las chicas / Y flechas de todos los colores apuntan los lugares en los alrededores / Donde deliberaba sobre las semanas berlinesas / Y muchos cuadrados rojos marcarían los aposentos / Del amor de la más baja especie o del amor más albergado del viento. GS II. (Benjamin, 2009, p. 714)

Este es un texto fundador, según Bolle (1996, p. 44), por instaurar un "doble código, simultáneamente pictográfico y literario" y por eso ofrece una clave privilegiada para descifrar el mapa de la ciudad constituido por las siglas del modelo de los Pasajes.

Para adentrarse en la complejidad de la grafiticiudad es necesario comprender la noción de cartografía y percibirla como un rizoma. El uso que Deleuze y Guattari hacen de ese concepto es el de un modelo descriptivo o epistemológico en el que la organización de determinados elementos no sigue las líneas de subordinación jerárquica. El concepto de rizoma descrito a lo largo de Mil mesetas. Capitalismo y esquizofrenia (2004) puede funcionar como un punto para pensar la multiplicidad de la grafiticiudad, tanto espacial como en las producciones que ocurren en su interior.
Es posible pensar el concepto de rizoma como un tipo de líneas sin un centro determinado, ligadas a puntos de una forma binaria, subordinadas a la verticalidad y a la horizontalidad. Cualquier punto de un rizoma puede ser ligado a otro, que se rompe en cualquier lugar y retoma su forma según una de sus líneas o según otras líneas (Deleuze y Guattari, 2004, pp. 15-18). Un rizoma no empieza ni acaba, siempre está en el medio, entre las cosas, interser, intermezzo (Deleuze y Guattari, 2004, p. 29). El rizoma se refiere a un mapa:

El mapa es abierto, conectable en todas sus dimensiones, desmontable, alterable, susceptible de recibir constantes modificaciones. Puede ser roto, alterado, adaptarse a distintos montajes, iniciado por un individuo, un grupo, una formación social. Puede dibujarse en una pared, concebirse como una obra de arte, construirse como acción política o como una meditación (Deleuze y Guattari, 2004, p. 18).

Un punto importarte en Mil mesetas es la idea de que "el mapa no reproduce un inconsciente cerrado sobre sí mismo, lo construye. Contribuye a la conexión de los campos, al desbloqueo de los cuerpos sin órganos, a su máxima apertura en un plan de consistencia" (Deleuze y Guattari, 2004, p. 18). Otro aspecto destacado en el rizoma es el hecho de tener múltiples "entradas" y comportar a veces una "nítida distinción entre línea de fuga como corredor de desplazamiento y los estratos de reserva o de vivienda". El mapa es una cuestión de performance. 
En la cartografía de la grafiticiudad, la percepción no se hará en un punto ni en órdenes, serán solo líneas y trayectos a ser construidos. Cada vez que hay una ruptura en el rizoma, las líneas segmentarias explotan en una línea de fuga que también es parte del rizoma: las líneas no paran de remitir unas a otras en una creación laberíntica que puede ser generada espontáneamente. Es decir, la cartografía en la grafiticiudad se construye a partir del descubrimiento de un espacio por recorrer; por tanto, estamos hablando de un espacio narrativo visual que el caminante elegirá. La construcción narrativa en este espacio ocurre como un hipertexto, una construcción de performance particular, una percepción de recorridos que pierden lo que hayan sido.

\section{La ciudad y sus intersticios narrativos}

En varios estudios, Henri Lefebvre defiende que el espacio, por ser un producto social, supone contradicciones de la realidad y revela diferencias y particularidades contextuales. Construido así, el espacio luego se vuelve "abstracto" con la fuerza de la razón estética y de las imágenes. La experiencia inmediata y sensible puede "reprimir la abstracción al retirar el estancamiento y la homogeneidad artificial del concepto de espacio", escribe en La revolución urbana; o sea, "el espacio urbano se convierte en el enclave donde se opera el contacto entre las cosas y las gentes, donde tiene lugar el intercambio" (Lefebvre, 1970, p. 8).

En La producción del espacio (2013), el sociólogo francés apunta tres instantes en esa producción social del espacio: a) el espacio "concebido", que es el de la representación abstracta traducida por un pensamiento capitalista estático y distante de lo real; b) el "percibido", surgido de la intermediación entre el orden distante y próximo, con los desdoblamientos de prácticas espaciales surgidas en los actos y relaciones específicos de la formación social, y c) el "vivido", que denota las diferencias en relación con el modo de vida programado. En un corto análisis, percibimos que no hay una inmutabilidad entre las dimensiones espaciales y, por eso, nada impide que el espacio "concebido" absorba el espacio de las representaciones (vivido).

Michel De Certeau (2000) concibe el espacio asociado a un lugar conducido en un desplazamiento, un "cruzamiento de objetos móviles" o un "lugar practicado". "La ciudad, como nombre propio, ofrece de este modo la capacidad de concebir y construir el espacio a partir de un número finito de propiedades estables, aislables y articuladas unas sobre otras" (De Certeau, 2000, p. 106). Él destaca que sin la noción de movilidad no sería posible que hubiera espacio, por lo que quedarían solo lugares fijos e inmutables o no-lugares.

En El murmullo de las imágenes, Josep M. Català retoma esa discusión sin tratar el no-lugar como local en que desaparece la ciudad. Él sugiere que el no-lugar, espacio no común por excelencia, se transformó finalmente en "un lugar común". Pero el éxito de esta noción, continúa, "obedece al hecho de que, en nuestra sociedad, sumamente codificada, donde todos los espacios, públicos y privados, están bajo 
control y solo permiten el uso institucional establecido, el no-lugar, la heterotopía, se convierte en una zona de misterio". Y que, por lo tanto, suscita todo tipo de atención, "desde la curiosidad hasta el rechazo, al tiempo que permite e impulsa la reconfiguración de las acciones y los discursos" (Català, 2012, p. 59).

La ciudad posee muchos no-lugares, comolos terrenos baldíos, sin edificaciones o espacios en que existieron edificios que hoy desaparecieron. El propio deterioro de la ciudad crea los no-lugares y, si queremos recurrir a la conferencia $D e$ los espacios otros, dictada por Foucault en el Círculo de Estudios Arquitectónicos en 1967, en los propios hoteles y las zonas de calles de pasajes con funciones concretas pueden existir no-lugares.

Después de entender las nociones de espacio, lugar y no-lugar, se puede pensar en la grafiticiudad que transforma la noción del no-lugar en el espacio de prácticas subversivas de pertenencia, de narrativas visuales que tienen el objetivo de narrar para "saber quiénes somos". Solo a través de las narrativas es que construimos nuestra identidad, nuestra pertenencia en el mundo. $\mathrm{O}$ en las palabras de De Certeau: "un lenguaje, desde que se lo habla - desde que es respirableinvolucra señales, fuentes, una historia, una iconografía, en suma, una articulación de 'autoridades'" (De Certeau, 1999, p. 30). El propósito transgresor y rebelde de los artistas urbanos es posicionarse ante las metrópolis como la "existencia" de una voz que es imagética y que posee una fuerza emocional.

En la metrópolis, el deambular es continuo, pesado o ligero, y la percepción de las imágenes se da por medio de "montajes subjetivos" que organizan "operaciones especulativas". Estas se pueden relacionar a las técnicas urbanísticas, que a su vez clasifican espacialmente las cosas teniendo como base la tradición del arte de la memoria, sobre la que Francis Yates realizó una brillanteinvestigación. La práctica del montaje subjetivo implementa la poética de la flânerie, perdida hoy, pero exaltada por Baudelaire, y que Benjamin consideraba símbolo de la modernidad: el aislamiento en la multitud, el anonimato y la experiencia del choque. La ciudad se transformó en un paisaje sin límites que contiene en ella, y a través de ella, un laboratorio de experimentaciones visuales. Si la posmodernidad sepultó el flâneur y la flânerie, hizo renacer también la figura de artistas transgresores que se apropian de los no-lugares y los transforman en espacios ritualistas de experiencias revelando el axioma de la movilidad. Un estado de neo-flânerie que permite desplazarse en la complejidad de la grafiticiudad y convivir en los meandros y entrañas de lo cotidiano, dejando marcas de pertenencia e identidad $^{6}$. La grafiticiudad crea así un proceso relacional con los no-lugares en

6 El Ardepixo Coletivo realizó el ensayo visual São Paulo, a capital da pixação! (2017). Estamos ante un nuevo tipo de flâneur: el flâneur electrónico que expande nuestro planteamiento de visión de trávelin a partir del uso del dron. 
el intento de aprehender la ciudad en todo su conjunto para, al final, totalizar esos espacios urbanos, haciendo emerger sus singularidades, generando la visión de un territorio que no quiere ser anónimo o transitorio en el nivel de la movilidad.

La visión en la grafiticiudad asimila de la cultura cinematográfica todos los intentos de síntesis del movimiento y lo que fue suprimido en el siglo $\mathrm{xx}$, con las interminables discusiones sobre montaje y realismo que están en proceso de recuperación y relectura en el siglo xxI.

El montaje en el cine es una conjunción de mundos que crea un sentido. En la grafiticiudad, ese sentido es la adición, la suma que crea un paralelismo visual en vez de una continuidad. De forma clásica, una película está constituida de secuencias, unidades menores dentro de ella, marcadas por una función dramática o narrativa. Las secuencias, a su vez, están constituidas de escenas, dotadas de unidades espacio-temporal. "El montaje construye escenas a partir de los pedazos separados [...]. La secuencia de estos pedazos no debe ser aleatoria pero sí correspondiente a la transferencia natural del observador imaginario (que, al final, está representado por el observador)" (Pudovkin, 1983, p. 60).

En la grafiticiudad, el observador recoge fragmentos visuales e intenta crear secuencias lógicas dando significado a una narrativa subjetiva 7 Él asume la cámara y el papel de ensamblador, y lo hace para narrar una historia o reorganizar un guion visual o simplemente organizar la información que se le ofrece de forma fragmentada, dividida e interconectada.

En la grafiticiudad, además de espacio y tiempo, es necesario considerar el ritmo, o mejor, la velocidad (Freire, 1997). La percepción de las imágenes y de los mensajes ocurre a través de montajes subjetivos después del desplazamiento del cuerpo del observador en el espacio de un recorrido urbano. Esto instaura una nueva percepción del objeto en un recorrido urbano, es a eso que llamamos visión en estado de trávelin.

Lev Manovich plantea que, a diferencia de las narraciones literarias, en el teatro y en la pintura bastan solo las técnicas colocadas en escena. En el caso de una escultura o arquitectura, "el espectador tiene que mover todo su cuerpo para experimentar la estructura espacial" (Manovich, 2006, p. 104); de esa misma manera se da nuestra relación con la ciudad y con los elementos visuales en el paisaje: es necesario circular, deambular, caminar, para obtener el efecto de trávelin. Así, la percepción de las imágenes y de sus mensajes se vuelve "en estado de trávelin"; es decir, el desplazamiento se convierte en una experiencia fundamental que permite

7 Para percibir las posibilidades de esta alegoría, el libro El francotirador paciente, de Arturo Pérez Reverte (2013), es una referencia, como también la película Historias de Lisboa (1994), de Wim Wenders. 
escapar de la ordenación espacial de la mirada para entrar en los no-lugares, lo que seguramente nos lleva a una "transterritorialidad" geográficamente circunscrita.
La interacción, el movimiento urbano y el flujo social acaban por crear una secuencia infinita de desorden de lo cotidiano y por apropiarse de imágenes que se ligan al desplazamiento entre la frontera del lugar y del no-lugar (véase la figura 2).

Figura 2. La visión en estado de trávelin

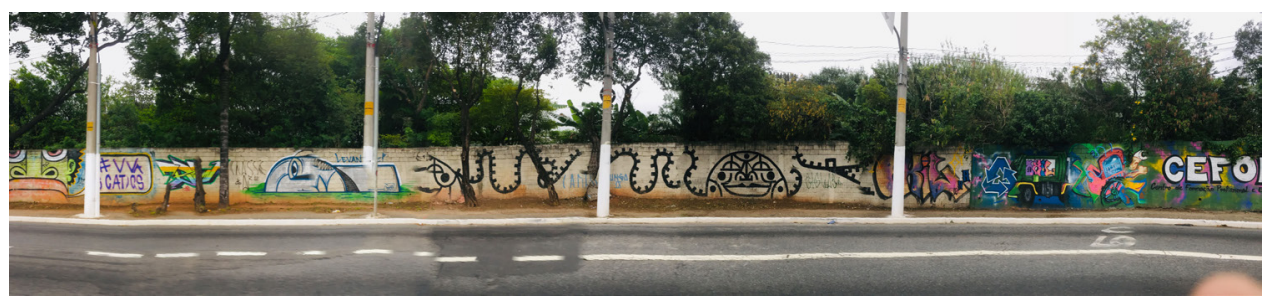

Autopista Marginal Tietê, São Paulo, Brasil. La obtención de esta imagen solo es posible por medio de un montaje fotográfico panorámico.

Fuente: archivo personal de los autores

La convivencia perceptiva y sensorial en la plataforma de la grafiticiudad va más allá de la concepción simplista de ocupación de un no-lugar. Detrás de gestos y voces rebeldes, es posible percibir la intención de una construcción simbólica que retira el carácter insólito del no-lugar y crea el imaginario urbano provocado por percepciones de la experiencia del observador.

Precisemos este punto. La visión en trávelin asociada a la movilidad pasa a significar la presencia en la realidad urbana $\mathrm{y}$, sobre todo, la acción sobre ella (véase la figura 3). No hablamos de una cristalización simbólica imaginaria, sino de la capacidad de interferir en la percepción que tenemos del no-lugar y en su transformación. Para De Certeau, el caminar

selecciona y fragmenta el espacio recorrido; salta los nexos y las partes enteras que omite. Desde este punto de vista, todo andar sigue saltando, o jugando, como el niño que anda "en un solo pie". $\mathrm{El}$ andar practica la elipsis de posiciones conjuntivas. (De Certeau, 2000, p. 114)

Transforma la relación del arte con el lugar, ya que lo expande, abriendo sus territorios. La caminata desestabiliza e inventa otras realidades que, por sí solas, ya se presentan móviles e inestables. 
Figura 3. Elevado João Goulart, São Paulo

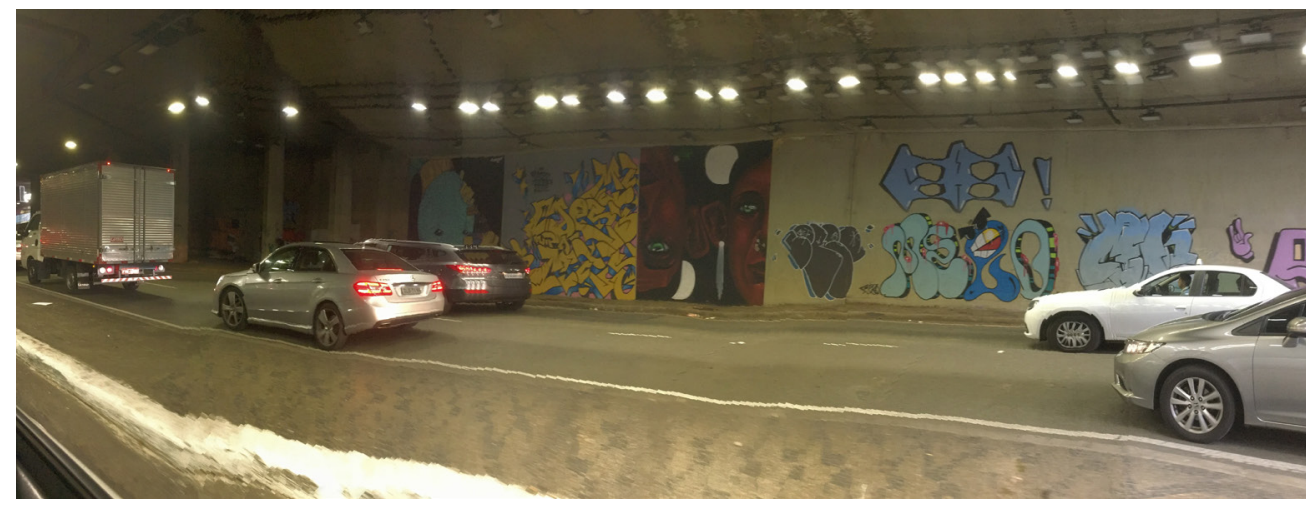

El observador en trávelin se apropia de partes menores, con el propósito de componer un todo mayor, una operación potencializada por el proceso que Josep Català llama de interfaz.

Fuente: archivo personal de los autores

\section{Campo visual y grafiticiudad}

El campo visual pasa a ser organizado de manera determinada y ese campo se convierte en una superficie de inscripciones y un espacio de aglutinación de perspectivas y lenguajes. Genera, por tanto, una nueva visualidad en la que nuestra mirada cambia de la situación de paneo para desplazarse lateralmente, multiplicando los puntos de vista. Desaparece el movimiento y los objetos se estructuran según la distancia, no según la impresión que tenemos de ellos y surge la idea de profundidad, que "transforma las valoraciones sensitivas y emocionales en evaluaciones espaciales y geométricas" (Català, 2011, p. 121).

Pero el carácter singular de la producción de sentido acontece cuando consideramos la grafiticiudad como un campo visual informacional por constituir un espacio de circulación de informaciones (véase la figura 4). La percepción, según Lucrecia d'Alessio Ferrara (1999), "es información en la misma medida en que la información genera información" (p. 153). La investigadora plantea que el espacio y la información son elementos interdependientes, ya que no es posible concebir, aprehender un espacio sino a través de los usos y hábitos derivados del modo de producción que los caracteriza, de la misma manera que los usos y hábitos constituyen la manifestación concreta del lugar urbano, en la misma medida en que el lugar es manifestación concreta del espacio. La percepción ambiental sería, para Ferrara, una operación en que el "uso y los hábitos son signos del lugar informado que solo se revelan en la medida en que son sometidos a la operación que expone la lógica de su lenguaje" (p. 153). 
Figura 4. La organización de fragmentos

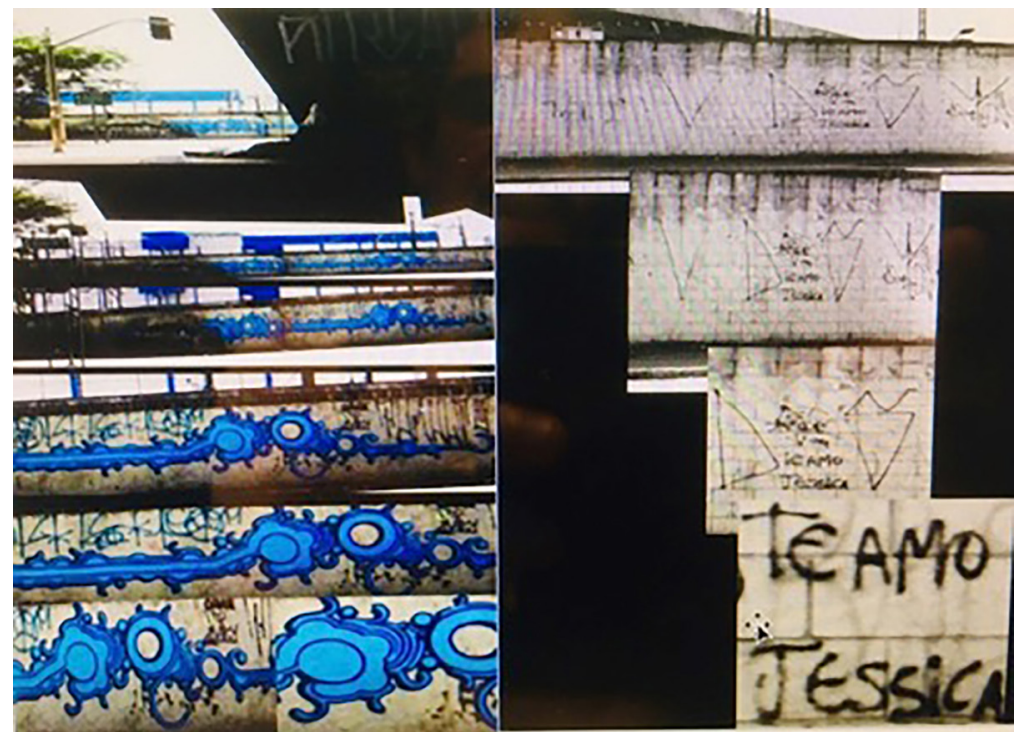

La organización de fragmentos es un proceso creativo y complementario. Para aprehender la información del espacio, es necesario reducir a fragmentos, transformar en lugar informado. Elaboración propia

Fuente: archivo personal de los autores

La grafiticiudad es un sistema visual fragmentado y dialéctico, y para entender su complejidad se hace necesario el supuesto de que la imagen, la simultaneidad de acontecimientos y la preferencia del espacio sobre lo temporal son inherentes: la imagen, incluyendo la imagen en movimiento, es capaz de presentar varias "capas de acontecimientos a la vez sin prácticamente proponérselo" (Català, 2005, p. 46).

Si consideramos que la visión quedó condicionada a la visualidad cinematográfica, y que no existen "imágenes puras", conceptualmente pensamos que el observador, en el "montaje subjetivo", reorganiza temporal, espacial y mentalmente las imágenes, transformándolas en reflexiones visuales, pues ellas están abiertas a las superposiciones y combinaciones arbitrarias que materializan la imagen en una nueva "arquitectura del imaginario". Como Stan Brakhage refleja, "'ver es fijar... contemplar' y un ojo refleja la 'pérdida de la inocencia' y, desde temprano, aprende a 'clasificar percepciones'”' (1983, p. 341).

El sentido de la visión, según Català en A Forma do Real. Introdução aos estudos visuais (2011), nos ofrece experiencias que parecen tan inmediatas que tenemos la sensación de ser capaces 
de comprenderlas rápidamente. $\mathrm{Y}$, en consecuencia, lo mismo sucede con las imágenes, que parecen ser una traducción directa de lo que vio su autor. Tal vez es por eso que, en algunas culturas, "ver es comparable con comprender", tanto que tienen la expresión "ver para creer" (pp. 252-253). O sea, hay una serie de patrones preconcebidos que "delimita, filtra y adjetiva lo que vemos" y configura la manera de "representar lo que vemos", estructurando nuestro imaginario.

El imaginario personal es relativo a nuestra cultura visual particular. Son aquellas imágenes que conocemos y que nos afectan personalmente. [...] El imaginario social corresponde a la visualidad relativa a la sociedad en la que estamos inmersos. Existen en diferentes grados, que pueden ir desde el entorno social inmediato [...] a una clase social. El imaginario cultural, referente a la visualidad cultural [...] donde cada sociedad dicta lo que puede ver, pero también como se puede ver. El imaginario antropológico se relaciona con las estructuras más profundas que dan lugar a la formación de imágenes (Català, 2011, pp. 252-253).

\section{Estructuras imaginarias de la imagen en la grafiticiudad: montaje subjetivo y reapropiación del no-lugar}

En las ciudades, las imágenes son dialécticas por naturaleza y destituidas de marcos, pues recogen de la urbe y de su tiempo la dispersión y lo efímero. Ellas se componen de "residuos y vestigios" de la vida cotidiana, que el coleccionista benjaminiano transforma en algo posible para la construcción de una historia-memoria. Así, la actuación de ese coleccionista se vuelve también dialéctica, pues considera la relación con el pasado (un no-lugar) en la intención de despertar algo que ya está allí en estado latente, de sueño, a la espera de una reapropiación.

La grafiticiudad se convierte en una heterotopía, un concepto de la geografía humana elaborado por Foucault que describe lugares y espacios que funcionan en condiciones no hegemónicas, o sea, un espacio con múltiples capas de significación o de relaciones con otros lugares cuya complejidad no puede ser vista inmediatamente. Para Català, en El murmullo de las imágenes. Imaginación, documental y silencio (2012), esos espacios heterotópicos están situados o en realidad están inmersos en las representaciones. Unos son espacios transitables, son escenarios para la imaginación; otros son espacios dentro de la estructura de la representación, que son "agujeros efectuados en el espacio diegético que conectan con la realidad, pero, a través de este movimiento, permiten que lo real sea invadido también por el imaginario" (p. 70). Así, según Català, "lo que encontramos, pues, en las representaciones son heterotopías que alegorizan los espacios heterotópicos reales. Nos presentan la estructura imaginaria de los mismos, aquella que les adjudica un valor natural que es puramente imaginario" (Català, 2012, p. 70).

Cuando se introduce a Walter Benjamin en esta discusión, en cierto modo se aproxima también a las ideas de 
Aby Warburg, pues las imágenes producidas en la grafiticiudad se vuelven imantadas de historia, de una existencia de gestos que provoca la memoria, o una "imagen sobreviviente" surgida de las narrativas apropiadas de la movilidad y del desplazamiento urbano.

El énfasis en el aspecto visual es el eje central del método de Aby Warburg, que esbozó una teoría general de la memoria social basada en imágenes y con acento en las relaciones complejas entre lo visual y el significado, que necesariamente implica acciones rituales e imágenes mentales. Un punto importante es la relación entre imagen y narrativa, aquí considerada como el "montaje subjetivo" surgido de la percepción imagética y su emergencia y supervivencia con huellas mnemónicas.

La percepción en el "montaje subjetivo" crea un movimiento dialéctico entre el entrecruzamiento de tiempo y espacio. Al desplazarnos, accionamos y hacemos emerger metáforas visuales que progresan más allá de la mente y proyectan un ambiente real. Por tanto, el ritmo, el tiempo y la historia flotan en un flujo narrativo imagético, en el que los cambios de velocidad, las desaceleraciones y aceleraciones, las paradas provisionales, los desvíos, las bifurcaciones crean nuevos montajes subjetivos de percepciones de la realidad aprehendida. Para el transeúnte, el paisaje de la grafiticiudad puede parecer fragmentos de las varias ciudades contenidas en la ella. Lo que los artistas transgresores proponen es una comunicación que transita entre la agresividad y la pasividad del observador.

La visualidad en la grafiticiudad, incluso, tiene la intención de dar nuevos significados a espacios de reconocimiento, ya que los no-lugares fueron anteriormente espacios de convivencia, hoy cargados de anonimato y de presencia sin rostro. Nos referimos a espacios abandonados, así sean terrenos baldíos. Esos espacios evidencian el rostro de los artistas anónimos por medio de sus riesgos e inscripciones en una confrontación entre lo real y lo imaginario. Recorrer la ciudad supone intermediar las metáforas visuales y las realidades cotidianas.

Los movimientos cotidianos huyen de nuestros ojos, pero durante el proceso del montaje subjetivo es posible percibir con rara agudeza la fragilidad del cuerpo en el ambiente urbano, "un proceso de apropiación del sistema topográfico por parte del peatón" (De Certeau, 2000, p. 110). Esto se da por medio del encuentro perturbador entre el individuo y el espacio, entre la imagen privada y la pública, entre lo visible y lo no visible. Es en ese momento que despuntan los varios lazos entre las distintas narrativas y la construcción de imaginarios y memorias sociales.

El montaje subjetivo evoca la supervivencia de las imágenes en un ritual de una construcción de la historia en el gesto simple de los rebeldes visuales. Pero ese proceso es eficaz, pues pretende marcar en la memoria un momento particular y efímero del tiempo, como un anagrama, o 
sea, la imagen grabada que nos transmite reflejos futuros, haciendo de las intervenciones un acto político estético.

Los grafitis deben ser tratados como riegos mnemónicos y no solo como representaciones urbanas, en la medida en que comparten la misma complejidad (la conjunción de rasgos contradictorios) que define a cualquier imagen, cargada de realidades referidas a la verdadera naturaleza pictórica. El concepto de pathosformel, formulado por Warburg (2010), es un modo de explicar la transmisión de una memoria colectiva por medio de imágenes, y el concepto de supervivencia traduce la posibilidad de transmisión. La supervivencia no es un camino de continuidad del tiempo cronológico, sino de transmisión de contenidos con valores expresivos que no se extinguen por pathosformel.

Las imágenes en la grafiticiudad son producidas siempre en un contexto ritualista, en la perspectiva warburguiana de la transgresión y subversión: los grafitis son impensables sin la rebeldía, sin la ocupación no autorizada del espacio público. En este trabajo consideramos los grafitis autorizados como muralismo, tema que no por ahora no se discutirá. Estamos tratando de intervenciones urbanas realizadas sin apoyo institucional, que bordean el vandalismo y la criminalidad. Aquí se entiende ese acto como una forma más de "transgresión" en busca de voz en los espacios dominados por las publicidades institucionalizadas.

El grafiti, con su lenguaje artístico, opera más fácilmente en el nivel mnemónico y evoca una contemporaneidad marcada por la transgresión de la cultura contemporánea. Pero vale observar que "ante una imagen - tan reciente, tan contemporánea, lo que sea-, el pasado no cesa nunca de reconfigurarse, dado que esta imagen solo puede ser pensada en una construcción de la memoria, cuando no de una obsesión" (Didi-Huberman, 2008, p. 32).

Esto apunta a una herramienta para un futuro estudio de la grafiticiudad y sus posibilidades, en que las imágenes, dotadas de una vida póstuma, nos hagan recordar la idea de palimpsestos, de atravesar algunos periodos encubiertos y regresar constantemente, para posibilitar así su análisis. Y eso sucedería no de forma lineal, en que "un después" sería la consecuencia de "un antes" y estaría influenciado por él, sino al contrario: es un diálogo constante entre el pasado y el presente, sin la preocupación de registro del tiempo o localización espacial, pues, en la plataforma productora de la grafiticiudad, el caminante dialoga con imágenes de tiempos diferentes y las actualiza según sus elecciones.

\section{Pertenencia e identidad}

Cabe recordar que la grafiticiudad es inestable y tiene la capacidad de partir hacia otra dirección, por contener un estado de movilidad compleja dependiente de la propensión al movimiento y de la circulación urbana en que las identidades, tanto colectivas como individuales, no se manifiestan más. Pero es posible afirmar que los artistas 
transgresores buscan crear un paisaje de diálogos por medio de una búsqueda comunicacional e híbrida, confluencia de tensiones y de marca de pertenencia y territorialidad.

Buscar el pasado con la mirada que resignifica posibilita el surgimiento de otros códigos de lectura para el análisis de imágenes. En la grafiticiudad, al realizar un montaje de tiempos, tenemos la oportunidad de evaluar cómo se plantean las cuestiones del presente para el pasado y, en posesión de las respuestas obtenidas, cuestionar el tiempo actual. Con eso, el grafiti pasa a desempeñar el papel de un espacio de enunciación del propio comportamiento del hombre omitido en la sociedad contemporánea.

Estas intervenciones pasan a constituirse en voces que revelan puntos de conflictos existentes en varias esferas, en el campo político, artístico, ético y poético, o simplemente de la existencia contemporánea. En las calles, las personas tejen la geografía de la ciudad. La expresión de los artistas de la transgresión trata de lo ínfimo, ellos encuentran en la ciudad un espacio para comunicar las ensonaciones, manifestar las inquietudes y anhelos ante una metrópoli que propone un falso igualitarismo y homogeneización, llevando a la pérdida del sentido de pertenecer (véanse las figuras 5 y 6). Pero es importante señalar, en ese sentido, también las dimensiones política e ideológica que definen las narrativas gráficas de estos mensajes. Para los transgresores, la ciudad es un espacio de realización y un campo de investigación y de comunicación que presenta nuevas posibilidades de ver y de sentir. Y ellos, por medio de sus transgresiones gráficas, crean nuevas formas de relacionarse con ese espacio.

Figura 5. Ver la ciudad

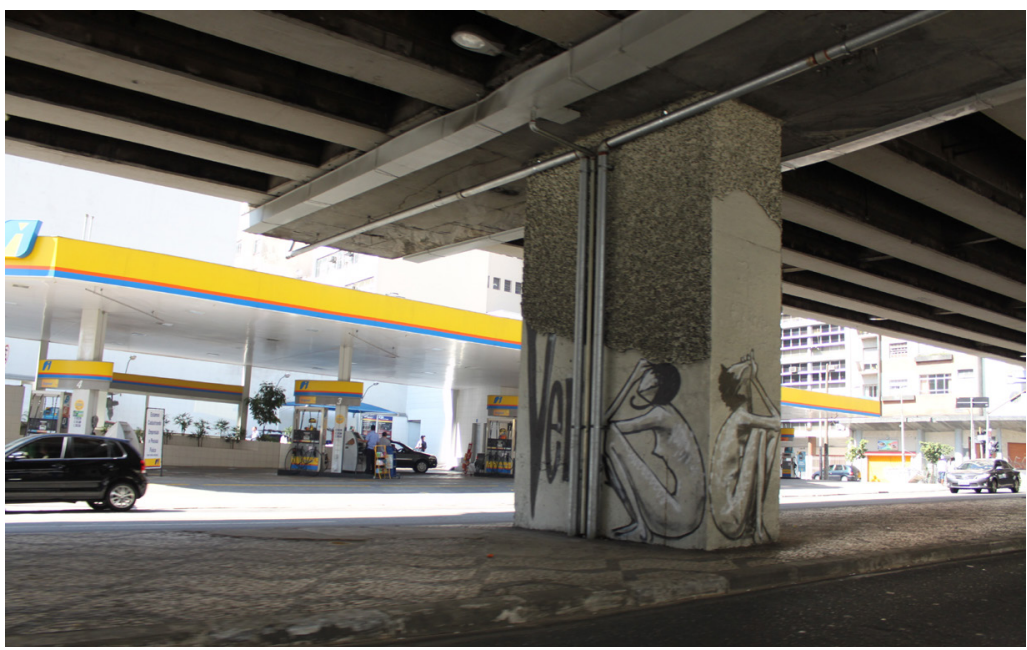

Mauro Neri, avenida São João, São Paulo

Fuente: archivo personal de los autores 
Algunos de esos trabajos se diluyen en la dinámica de la ciudad, al mismo tiempo que se aprovechan las posibilidades de fruición que el ambiente urbano propicia, pues la ciudad se mueve a un ritmo que se superpone a la obra de arte. Los carteles son encolados unos sobre otros en muy poco tiempo, e incluso las intervenciones de los artistas transgresores conviven con superposiciones palimpsestas, o incluso acciones de política pública, que cubren o borran esos registros. Hay una consciencia de que sus obras son efímeras y por eso mismo relegadas al olvido. De ahí la necesidad de la "estrategia" astuta (Bourdieu, 1990) y de la táctica de visibilidad.

Figura 6. Radial Leste, São Paulo

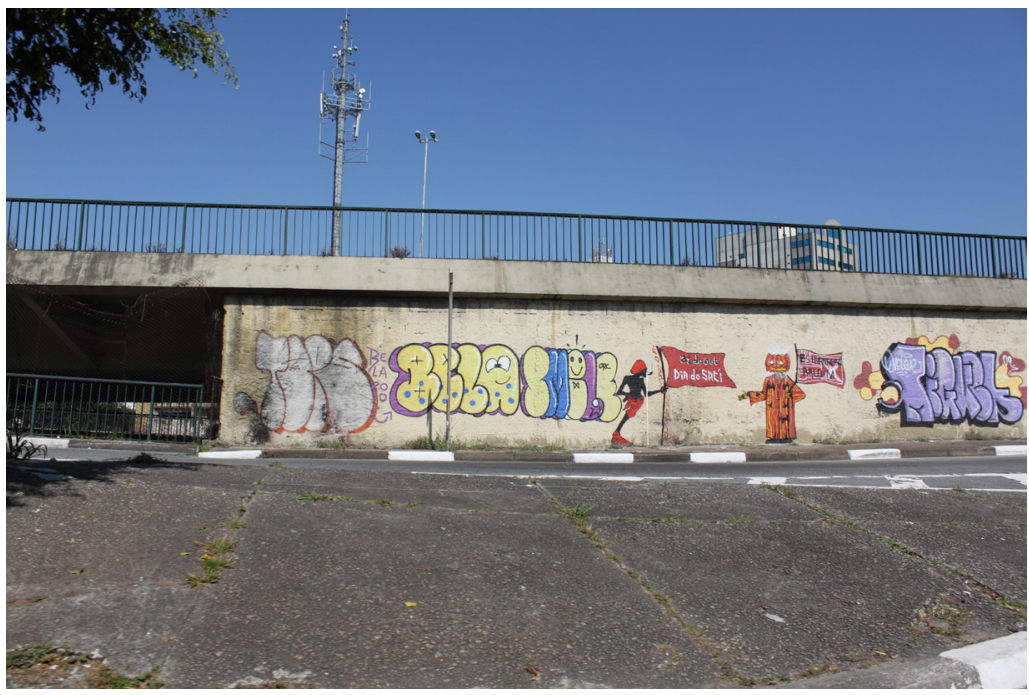

Fuente: archivo personal de los autores

La ciudad es un espacio humano de cultura y de comunicación. La cultura es el cultivo de las potencialidades humanas; la comunicación, el intercambio de esas potencialidades. Podríamos dar un paso más y pensar en la "configuración" de esas potencialidades: si solo se habla de "intercambio", se queda en el nivel informativo; si se habla de "configuración", se posibilita el sentido a partir del feedback y, por ende, el poder de la comunicación de posibilitar las potencialidades. La ciudad permitió y generalizó la experiencia de proximidad y también de distancia, y al mismo tiempo posibilita la organización a partir de las divisiones del espacio. Desde esta perspectiva, se puede entender la ciudad como un emblemático campo comunicacional, en que los 
comunicadores urbanos, al apropiarse de un espacio público, elaboran la información en contra de la publicidad, priorizando no un producto, sino la escala de lo humano ${ }^{8}$. Ellos provocan la visualidad de una experiencia, crean una relación con el observador, rompiendo cierta carga simbólica vehiculada en las ciudades. Reivindican pertenencia e identidad, provocan un debate sobre las relaciones sociales y ponen en jaque el concepto mismo de lo que es el arte. Rossana Reguillo nos recuerda que la identidad no es una esencia, se trata de un concepto relacional que supone simultáneamente un proceso de identificación y un proceso de diferenciación, lo que implica necesariamente una tarea de construcción. La identidad se construye en interacción con los otros, los iguales y los diferentes. La identidad instaura su propia alteridad. De la misma forma que sabemos que las identidades son históricas, en el pensamiento actual se abre un debate importante en torno a las identidades efímeras y cambiantes, que no serían más identidades, sino "identificaciones" (Reguillo, 2000, pp. 78-79). En ese punto, volvemos a encontrarnos con una cuestión que hemos rozado antes: la de la política.

El grafiti podría sugerir definitivamente una imposibilidad de la visión, pero por su carácter dialéctico y su inserción en el paisaje rescata algo que no se retrata, algo producido entre la mirada y el mundo, y que no es una simple representación, sino un acto político insertado en el contexto urbano. Como un arquitecto, estos transgresores exponen sus propias ciudades invisibles. Como objetos de cultura, esas inscripciones urbanas presentan simultáneamente una realidad material y una realidad simbólica. En ese diálogo de discontinuidades podemos establecer el lugar de las imágenes de la grafiticiudad como una obra, como montaje de tiempos, pues

una imagen, al contrario, es aquello en el que el Pretérito encuentra al Ahora en un relámpago para formar una constelación. En otros términos, la imagen es la dialéctica en suspensión. Porque la relación del presente con el pasado es puramente temporal y continua, la relación del Pretérito con el Ahora presente es dialéctica: no es algo que se desenvuelve, sino una imagen fragmentada. Solo las imágenes dialécticas son imágenes auténticas (es decir, no arcaicas); y la lengua es el lugar donde es posible acercarse a ellas. (Benjamin, como se citó en Didi-Huberman, 1998, p. 114)

En esa plataforma de producción imagética, el campo visual se convierte en una superficie de inscripciones y un espacio de aglutinación de percepciones y de lenguajes, entendiendo el término

8 Rossana Reguillo, en Pensar la ciudad desde la comunicación, plantea que "mirar la ciudad desde la comunicación implica, en primer término, trabajar la relación entre cultura objetivada y cultura incorporada, es decir, la observación de la presencia de agencias, instituciones, discursos y prácticas objetivadas en las representaciones de los actores urbanos" (Reguillo, 1995, p. 123). 
lenguaje en el sentido amplio. La grafiticiudad es, por lo tanto, proponer una nueva forma de visualidad, en que la mirada deja de ocupar una posición de planeo, desprovista de profundidad, para desplazarse lateralmente, multiplicando puntos de vista. La imagen así producida se vuelve compleja por estar asociada tanto a la propia dialéctica del espacio de producción como a lo que pretende representar.

La ciudad, lugar del intercambio social, adquiere su identidad al definirse como una especie de individualidad conglomerada, a que podríamos llamar un "contrato social". Pero la identidad de la ciudad, definida por sus leyes, depende de algún tipo de prohibición y exclusión. "La identidad del individuo exige el inverso: un esfuerzo constante de inclusión, una historia que recuerde a Gilgamesh que, para saber lo que cada uno es, son necesarios al menos dos hombres" (Manguel, 2008, p. 55).
Compuesta por líneas o rizomas, sin centro o periferia, la grafiticiudad expone la necesidad ancestral de búsqueda de identidad, la construcción de una narrativa en el territorio urbano, que tiene el propósito de dar expresión y contexto a las experiencias privadas, de tal modo que, reconocidas por el tejido social, las percepciones/expresiones individuales pueden adquirir un sentido de pertenencia compartido en la tensión entre ambas, que permite la coexistencia y confiere identidad.

La grafiticiudad, recurriendo a Maffesoli (1990), une elementos de varias identidades de tribus que se encuentran en un terreno común, sin fundir los diversos caracteres y voces en una identidad social exclusiva; así, lo que puede ser la raíz de un conflicto, en realidad entrelaza y convierte la maldición de Babel en una dádiva. Nadie es todo, nadie es nada: somos. Hemos participado, interactuamos, nos comunicamos, pertenecemos.

\section{Referencias}

Ardepixo Coletivo. (24 de septiembre del 2017). São Paulo, a capital da pixação! Recuperado de https://www.youtube.com/watch?v=8OyLzp_PVOU

Benjamin, W. (1989). Obras escolhidas III: Charles Baudelaire, um lírico no auge do capitalismo. São Paulo: Brasiliense.

Benjamin, W. (2009). Libro de los pasajes. Madrid: Akal.

Benjamin, W. (2012). El París de Baudelaire. Buenos Aires: Eterna Cadencia Editora.

Bolle, W. (1996). As siglas em cores no Trabalho das Passagens, de W. Benjamin. Estudos Avançados, 10(27), 41-77. http://dx.doi.org/10.1590/S0103-40141996000200003

Bolle, W. (2000). A fisiognomia da metrópole moderna: representação da história em Walter Benjamin. São Paulo: Editora da Universidade de São Paulo. 
Buordieu, P. (1990). Sociología y cultura. México: Grijalbo.

Brakhage, S. (1983). Metáfora da visão. En A experiência do cinema: antologia (pp.341-352). Río de Janeiro: Graal.

Careri, F. (2014). Walkscapes, el andar como práctica estética. Barcelona: Gustavo Gili.

Cassou, J. (1962). Panorama das artes plásticas contemporâneas. Lisboa: Editorial Estúdios Cor.

Català, J. M. (2005). La imagen compleja: la fenomenología de las imágenes en la era de la cultura visual. Bellaterra: Universitat Autònoma de Barcelona.

Català, J. M. (2011). A forma do real. Introdução aos estudos visuais. São Paulo: Summus Editorial.

Català, J. M. (2012). El murmullo de las imágenes. Imaginación, documental y silencio. Cantabria: Shangrila.

Costa, J. (2011). Ecología de la comunicación e interacción social. Pensar la Publicidad. Revista Internacional de Investigaciones Publicitarias, 4(2), 17-24. Recuperado de http://revistas.ucm.es/index.php/PEPU/article/view/PEPU1010220017A/15014

De Certeau, M. (1999). La cultura en plural. Buenos Aires: Ediciones Nuevas Visiones.

De Certeau, M. (2000). La invención de lo cotidiano I. Arte de hacer. México: Instituto Tecnológico y de Estudios Superiores Del Occidente.

Deleuze, G., y Guattari, F. (2004). Mil mesetas. Capitalismo y esquizofrenia. Valencia: Pre-textos.

Didi-Huberman, G. (2008). Ante el tiempo. Historia del arte y anacronismo de las imágenes. Buenos Aires: Adriana Hidalgo.

Ferrara, L. (1999). O olhar periférico. São Paulo: Editora da Universidade de São Paulo. Foucault, M. (2010). El cuerpo utópico. Las heterotopías. Buenos Aires: Nueva Visión.

Fontcuberta, J. (2010). O beijo de Judas: fotografia e verdade. Barcelona: Editorial Gustavo Gili. Lefebvre, H. (1970). La revolución urbana. Madrid: Alianza Editorial.

Lefebvre, H. (2013). La producción del espacio. Madrid: Capitán Swing Libros.

Lotman, I. M. (2000). La semiosfera III. Semiótica de las artes y de la cultura. Madrid: Ediciones Cátedra.

Lynch, K. (1998). La imagen de la ciudad. Barcelona: Editorial Gustavo Gili.

Maffesoli, M. (1990). El tiempo de las tribus. El declive del individualismo en las sociedades de masas. Barcelona: Icaria.

Manguel, A. (2008). As cidade das Palavras: história que contamos para saber quem somos. São Paulo: Cia das Letras.

Manovich, L. (2006). El lenguaje de los nuevos medios de comunicación. La imagen en la era digital. Buenos Aires: Paidós. 
Pesavento, S. J. (2004). Com os olhos no passado: a cidade como palimpsesto. Revista Esboços, (11), 25-30. Recuperado de https://periodicos.ufsc.br/ index.php/esbocos/article/view/334

Reguillo, R. (1995). Pensar la ciudad desde la comunicación. En J. Galindo y C. Luna (coords.), Campo académico de la comunicación: hacia una reconstrucción reflexiva (pp. 109-132). México: ITESO-Conaculta.

Reguillo, R. (2000). Identidades culturales y espacio público: un mapa de los silencios. Diálogos de la Comunicación, (59-60), 75-86. Recuperado de http://dialogosfelafacs.net/wp-content/uploads/2012/01/59-60-revistadialogos-identidades-cultural.pdf

Pudovkin, V. (1983). Métodos de tratamento do material (montagem estrutural). Os métodos do cinema. O direitor e o roteiro. En I. Xavier (org.), A experiencia do cinema: antologia (pp. 57-73). Río de Janeiro: Graal.

Warburg, A. (2010). Atlas Mnemosyne. Madrid: Akal.

\section{Bibliografía}

Català, J. M. (2010). La imagen interfaz. Representación audiovisual y conocimiento en la era de la complejidad. Bilbao: Universidad del País Vasco.

Didi-Huberman, G. (1998). O que nós vemos, o que nos olha. São Paulo: Editora 34.

Didi-Huberman, G. (2009). La imagen superviviente. Historia del arte y tiempo de los fantasmas según Aby Warburg. Madrid: Abada.

Foucault, M. (1984/s. f.). De los espacios otros. En P. Blitstein y T. Lima (trads.). Recuperado de http://yoochel.org/wp-content/uploads/2011/03/foucalt_ de-los-espacios-otros.pdf

Francastel, P. (1967). A imagem, a visão e a imaginação. Lisboa: Edições 70.

Francastel, P. (1976). O aparecimento de um novo espaço. En G. Velho (Ed.), Sociologia da arte III. Río de Janeiro: Zahar Editores.

Freire, C. (1997). Além dos mapas: os monumentos no imaginário urbano contemporâneo. São Paulo: Annablume.

Genette, G. (1989). Palimpsestos. La literatura en segundo grado. Madrid: Taurus.

Lefebvre, H. (1980). A vida cotidiana no mundo moderno. São Paulo: Ática.

Lefebvre, H. (1996). A linguagem e a sociedade. Lisboa: Ulisseia.

Scolari, C. (2015). Ecología de los medios. Barcelona: Gedisa.

Xavier, I. (1983). A experiência do cinema. Antologia. Río de Janeiro: Graal. 
